Check for updates

Cite this: Mater. Adv., 2021,

2,684

Received 13th November 2020,

Accepted 19th December 2020

DOI: $10.1039 / \mathrm{d} 0 \mathrm{ma} 00883 d$

rsc.li/materials-advances

\section{First synthesis of air-stable NiZn homogeneous alloy nanoparticles through chemical reduction $\dagger$}

\author{
Shinya Okamoto, iD *a Kohei Kusada, iD b Hiroshi Hashiba, ${ }^{\mathrm{b}}$ Satoshi Yotsuhashi ${ }^{\mathrm{a}}$ and \\ Hiroshi Kitagawa id b
}

\begin{abstract}
We successfully synthesized NiZn homogeneous alloy nanoparticles, which were mixed at the atomic level, for the first time through a chemical reduction method with sodium-naphthalenide as a reducing agent. The NiZn alloy nanoparticles were stable even in air for at least half a year, although $\mathrm{Zn}$ is typically easily oxidized.
\end{abstract}

Alloy nanoparticles have received considerable attention owing to the tunability of their chemical and physical properties based on control of their composition, ${ }^{1-5}$ particle size, shape, ${ }^{6-10}$ and mixing pattern. ${ }^{11,12}$ In addition, it has been reported that new types of alloy nanoparticles, such as $\mathrm{AgRh}^{13}$ and $\mathrm{PdRu}^{14}$ solid-solution alloy nanoparticles, have been synthesized by a chemical reduction process despite immiscibility of the constituent elements. ${ }^{15-19}$ Syntheses of new alloy nanoparticles give insights into materials science. For example, AgRh nanoparticles have hydrogen-storage ability, although neither $\mathrm{Ag}$ nor Rh show this property. PdRu nanoparticles also have a highly efficient CO-oxidizing catalytic activity. However, there remain challenges to establishing robust approaches to synthesizing alloy nanoparticles from arbitrary elements. Most reported alloy nanoparticles contain noble metals because noble metal nanoparticles are easier to be synthesized than non-noble metals through chemical methods owing to their relatively high electronegativities. Therefore, there have been few reports on alloy nanoparticles consisting of only non-noble metals synthesized by chemical methods.

In this report, we focus on a combination of the non-noble metals, Ni and $\mathrm{Zn}$. There have been several reports on catalysts containing $\mathrm{Ni}$ and $\mathrm{Zn}$. For example, Ni and $\mathrm{Zn}$ dispersed on an oxide support by an incipient wetness technique were capable

\footnotetext{
${ }^{a}$ Technology Division, Panasonic Corporation, 1006 Kadoma, Kadoma-City, Osaka 571-8508, Japan

${ }^{b}$ Division of Chemistry, Graduate School of Science, Kyoto University, Kitashirakawa-Oiwakecho, Sakyo-ku, Kyoto 606-8502, Japan

$\dagger$ Electronic supplementary information (ESI) available: TEM image, Rietveld refinement of XRD pattern, STEM images of the surface, EDX data of synthesized NiZn nanoparticles, STEM-EDX maps and XRD pattern of phase-separated nanoparticles. See DOI: 10.1039/d0ma00883d
}

of selective hydrogenation of acetylene. ${ }^{20}$ Nanoparticles synthesized from $\mathrm{Ni} / \mathrm{ZnO}$-coated carbon nanotubes gave selective conversion of cellulose into vicinal diols. ${ }^{21}$ Another study found that nanoparticles synthesized from $\mathrm{Ni}\left(\mathrm{NO}_{3}\right)_{2} \cdot 6 \mathrm{H}_{2} \mathrm{O}$ and $\mathrm{Zn}\left(\mathrm{NO}_{3}\right)_{2} \cdot 6 \mathrm{H}_{2} \mathrm{O}$ by a surfactant-aided polyol reduction method were an efficient catalyst for phenol gasification. ${ }^{22}$ These reports highlight the great potential of NiZn alloy nanoparticles as efficient catalysts. However, to the best of our knowledge, there have been no reports of uniformly mixed alloy nanoparticles of NiZn. The most successful result of this challenge was the synthesis of nanoparticles having a core-shell structure with $\mathrm{Zn}$ atoms in an Ni core by Jana et al. ${ }^{23}$ The difficulty in the synthesis of homogeneous Nizn alloy nanoparticles is attributed to the large differences in the chemical properties between Ni and Zn, such as their melting points (Ni: 1455 and Zn: $\left.420{ }^{\circ} \mathrm{C}\right),{ }^{24}$ electron negativities, and ease of oxidation in air.

Here, we demonstrate a chemical synthesis of homogeneous NiZn alloy nanoparticles with the use of sodium-naphthalenide as a reducing agent. Sodium-naphthalenide has a large reduction capability, and it has recently been used in the synthesis of $\mathrm{Zn}$ nanoparticles. ${ }^{25-27}$ The crystal structure was analyzed by synchrotron powder X-ray diffraction (XRD), and the detailed structure analysis was implemented with transmission electron microscopy (TEM) and scanning TEM (STEM) coupled with energy-dispersive X-ray spectroscopy (EDX).

NiZn nanoparticles were synthesized under an argon atmosphere using Schlenk techniques at room temperature. First, sodiumnaphthalenide solution was prepared. A flask containing naphthalene was filled with argon at room temperature. Then, tetrahydrofuran (THF) was injected by syringe, and cut sodium was dropped into the solvent. The solution was stirred for $12 \mathrm{~h}$. Second, a metal precursor solution was prepared by dissolving $\mathrm{NiCl}_{2}-\mathrm{CH}_{3} \mathrm{O}\left(\mathrm{CH}_{2}\right)_{2} \mathrm{OCH}_{3}(0.07 \mathrm{mmol})$ and anhydrous $\mathrm{ZnCl}_{2}$ $(0.14 \mathrm{mmol})$ in THF $(17 \mathrm{~mL})$. The color of the precursor solution quickly turned black on injection of the sodium-naphthalenide solution $(5 \mathrm{~mL})$, which indicated the formation of metal nanoparticles. After stirring for $5 \mathrm{~min}$, the as-synthesized nanoparticles were removed to air and separated with a centrifuge at $210000 \mathrm{~g}$-force (50000 rpm) for $2 \mathrm{~h}$. Finally, the nanoparticles 
were filtered with methanol and dried under vacuum. The dried powder was sintered at $300{ }^{\circ} \mathrm{C}$ for $1 \mathrm{~h}$ in hydrogen. The nanoparticles were obtained with yields of $90-95 \%$.

We note the importance of drying the starting material for the $\mathrm{Ni}$ precursor. When $\mathrm{H}_{2} \mathrm{O}$ is included in the $\mathrm{Ni}$ salt, it appears to lower the reduction ability of sodium-naphthalenide. $\mathrm{NiCl}_{2}-\mathrm{CH}_{3} \mathrm{O}\left(\mathrm{CH}_{2}\right)_{2} \mathrm{OCH}_{3}$ provided the best results among several kinds of Ni precursors in this study. The solubility of the precursors in the solvent should also be carefully considered to obtain homogeneous alloy nanoparticles. Most commercial $\mathrm{Ni}$ compounds, such as $\mathrm{Ni}\left(\mathrm{NO}_{3}\right)_{2}, \mathrm{Ni}\left(\mathrm{OCOCH}_{3}\right)_{2}, \mathrm{NiSO}_{4}$, and $\mathrm{NiCO}_{3}$, were practically insoluble in THF. Moreover, the density of the sodium-naphthalenide should be adjusted to an appropriate level.

The synthesized nanoparticles were characterized by TEM imaging. Fig. S1 (ESI $\dagger$ ) shows that the nanoparticles were synthesized by a sodium-naphthalenide reduction without any stabilizing agents.

The crystal structure of the synthesized nanoparticles was investigated with the use of synchrotron powder XRD at $303 \mathrm{~K}$, at the beamline BL02B2, SPring- $8 .{ }^{28}$ Fig. 1 shows the XRD patterns of the synthesized NiZn nanoparticles and $\mathrm{Ni}$ and $\mathrm{Zn}$ powder. The diffraction patterns of $\mathrm{Ni}$ and $\mathrm{Zn}$ had face-centered cubic (fcc) and hexagonal close-packed (hcp) structures, respectively. The XRD pattern of the synthesized nanoparticles corresponds to $\beta_{1}$-phase of a NiZn intermetallic alloy with a tetragonal structure (Fig. S2, ESI $\dagger$ ). ${ }^{29}$ We note that peaks of the Ni, Zn mono-metals, or other by-products, such as $\mathrm{ZnO}$ were not observed in the patterns of the nanoparticles. This result confirms that the NiZn alloy nanoparticles were uniformly synthesized.

To investigate the detailed structure of the synthesized nanoparticles, we performed STEM observations. Fig. 2a shows a high-angle annular dark-field STEM (HAADF-STEM) image of the synthesized nanoparticles. Fig. $2 \mathrm{~b}$ and $\mathrm{c}$ show STEM-EDX maps corresponding to $\mathrm{Ni}-\mathrm{K}$ and $\mathrm{Zn}-\mathrm{K}$, respectively. Fig. $2 \mathrm{~d}$ is an

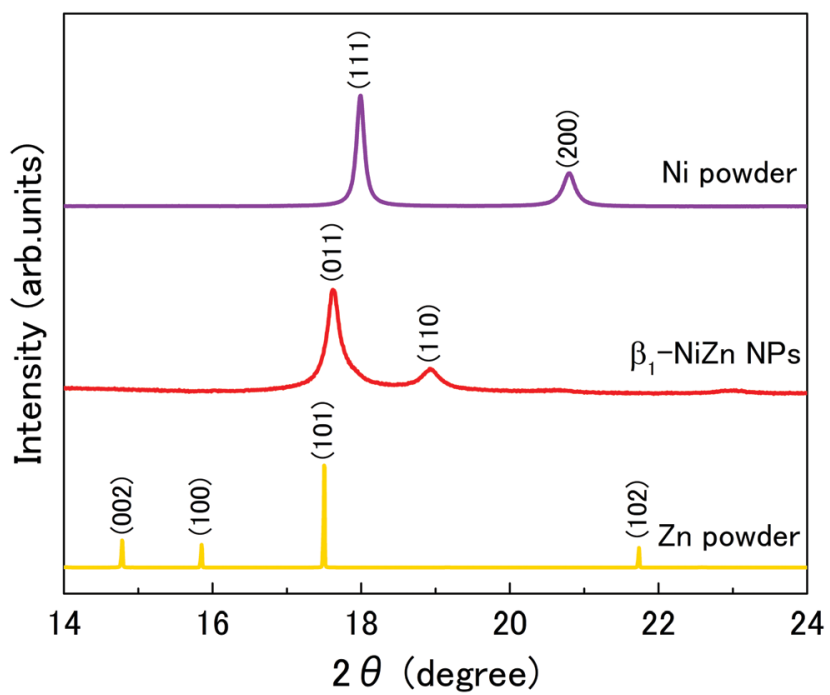

Fig. 1 Synchrotron powder XRD patterns of Ni powder, NiZn nanoparticles, and $\mathrm{Zn}$ powder at room temperature. The radiation wavelength was $0.636038 \AA$
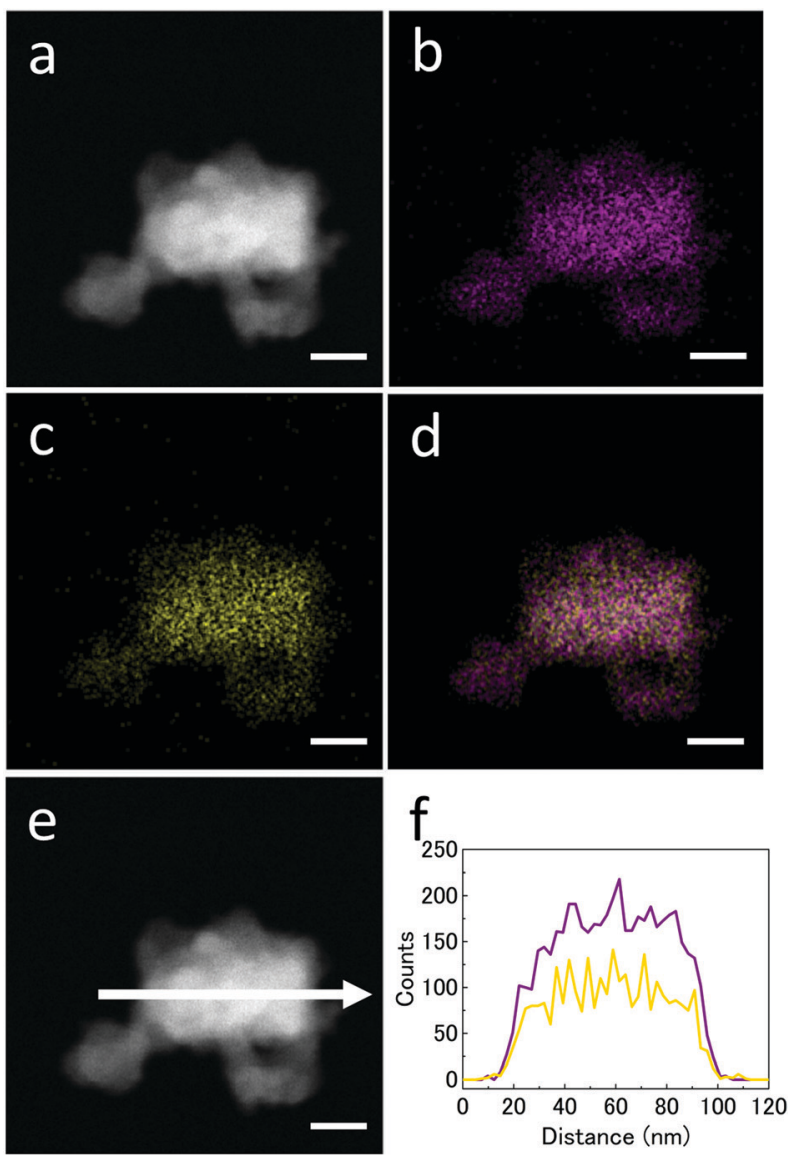

Fig. 2 (a) HAADF-STEM image, (b) Ni-K STEM-EDX map and (c) Zn-K STEMEDX map of (a). (d) Overlay image of (b) and (c). (f) EDX line profiles across the NiZn nanoparticle along the arrow shown in (e). Ni and $\mathrm{Zn}$ are shown as purple and yellow lines, respectively. Scale bars correspond to $25 \mathrm{~nm}$.

overlay map of the $\mathrm{Ni}$ and $\mathrm{Zn}$ chemical distributions. Fig. $2 \mathrm{f}$ shows EDX line scan profiles of the NiZn alloy nanoparticle shown in Fig. 2e. The line profiles confirmed that Ni and Zn were uniformly distributed over the whole nanoparticles. The average stoichiometry from the EDX data was $\mathrm{Ni}: \mathrm{Zn}=0.59: 0.41$. These results indicate that the synthesized nanoparticles are uniform NiZn alloy without any phase separation. We further investigated the detailed structure of the NiZn nanoparticles at atomic resolution. Fig. 3a and b show a high magnification HAADFSTEM image and line profiles of $\mathrm{Ni}$ and $\mathrm{Zn}$ for the NiZn nanoparticle recorded in the area along the black arrow shown in Fig. 3a, respectively. A regular arrangement of $\mathrm{Ni}$ and $\mathrm{Zn}$ atoms was clearly observed. Fig. 3d and e show STEM-EDX maps corresponding to Ni-K and $\mathrm{Zn}-\mathrm{K}$, respectively. Fig. $3 \mathrm{c}$ is an overlay map of Fig. 3d and e. The lattice image corresponds to the atomic arrangement of the $\beta_{1}$ phase of a NiZn intermetallic compound from the [010] zone axis, shown in Fig. 3a. These results indicate the successful synthesis of novel NiZn alloy nanoparticles where both $\mathrm{Ni}$ and $\mathrm{Zn}$ were uniformly mixed at the atomic level by a sodium-naphthalenide reduction method.

We also investigated the surface structure of the NiZn alloy nanoparticles. Fig. S3a and S3b (ESI $\dagger$ ) show bright-field (BF) 

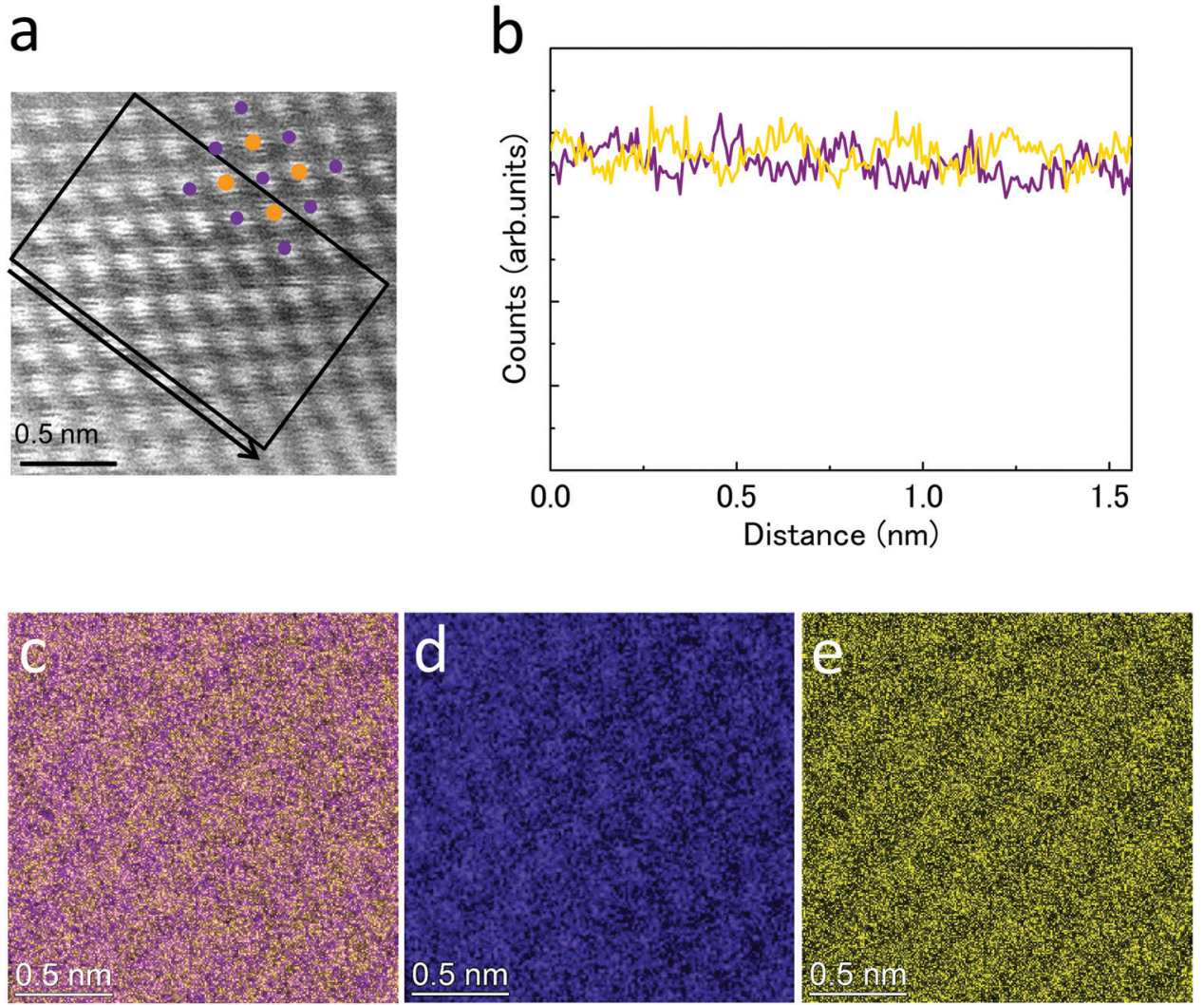

Fig. 3 (a) HAADF-STEM image and a model structure of $\beta_{1}$ phase of NiZn viewed from [010] zone axis (purple: Ni, yellow: Zn) (b) EDX line profiles of Ni (purple) and Zn (yellow) for a NiZn particle recorded in the area along the arrow shown in the STEM image (a). (c) Overlay image of (d) and (e). (d) Ni-K STEM-EDX map and (e) Zn-K STEM-EDX map of the NiZn nanoparticle.

STEM and HAADF-STEM images of a NiZn nanoparticle, respectively. A thin layer with a thickness of approximately $2 \mathrm{~nm}$ was observed at the surface of the nanoparticle. Fig. S4 (ESI $\dagger$ ) shows the average stoichiometries determined from the EDX data. These results indicate that the thin layer consisted of NiZn oxide. In addition, the ratio of oxygen at the edge of the nanoparticle was greater than that at the center. Hence, oxidation occurred only at the surface after air exposure of the nanoparticles and the NiZn alloy nanoparticles were stable in air for more than half a year, although $\mathrm{Zn}$ is typically extremely easily oxidized. This result might be attributed to surface passivation by $\mathrm{Ni}$.

The NiZn nanoparticles could be crystallized by sintering in a hydrogen atmosphere, although these were amorphous-like after the strong reduction reaction when the nanoparticle was an atomic-level mixture. When we adopted a different reduction process, phase-separated nanoparticles were obtained (Fig. S5 and S6, ESI $\dagger$ ). In this case, the reduction rate of the $\mathrm{Zn}$ and Ni ions was not well controlled. Thus, we could not obtain NiZn alloy nanoparticles even if they were sintered under the same conditions. In other words, control of the reduction speed is the key to realizing NiZn alloy nanoparticles, which are mixed at the atomic level rather than the annealing process in a hydrogen atmosphere. This technique enables controlled simultaneous reduction of several materials and might be applied to the synthesis of alloy nanoparticles of a variety of combination of elements.

In conclusion, we report the successful synthesis of NiZn homogeneous alloy nanoparticles that do not contain any noble metals by a sodium-naphthalenide reduction method. The synthesized nanoparticles were uniformly mixed at the atomic level and formed a $\beta_{1}$ phase NiZn intermetallic compound. These results indicate that $\mathrm{Zn}$ and $\mathrm{Ni}$ ions were concurrently reduced in a liquid phase through control of the reduction speed with a strong reduction agent. The crystal structure of the synthesized nanoparticles was different from those of their constituent elements. The alloy nanoparticles would exhibit new chemical and physical properties unlike those of the constituent $\mathrm{Ni}$ and $\mathrm{Zn}$ mono-metals. In addition, the NiZn nanoparticles were stable even in air, although $\mathrm{Zn}$ particles are typically easily oxidized. This synthetic technique based on a strong reduction agent might be applied to other alloy nanoparticles in a variety of combinations of elements, leading to the development of new materials with excellent properties.

\section{Conflicts of interest}

There are no conflicts to declare. 


\section{Acknowledgements}

We thank Dr H. Kobayashi, Dr S. Kinoshita of Kyoto University for supporting the synthesis of NiZn nanoparticles. We are also thankful to Dr A. Sakai, Dr K. Nakajima, Dr S. Kusama, Dr H. K. Sato and Dr T. Saito of Panasonic Corporation for helping us to synthesize and characterize the nanoparticles.

\section{Notes and references}

1 G. L. Brett, Q. He, C. Hammond, P. J. Miedziak, N. Dimitratos, M. Sankar, A. A. Herzing, M. Conte, J. A. Lopez-Sanchez, C. J. Kiely, D. W. Knight, S. H. Taylor and G. J. Hutchings, Angew. Chem., Int. Ed., 2011, 50, 10136-10139.

2 X. Liu, A. Wang, X. Wang, C. Y. Mou and T. Zhang, Chem. Commun., 2008, 3187-3189.

3 W. Chen, J. Kim, S. Sun and S. Chen, Langmuir, 2007, 23, 11303-11310.

4 J. Zhang, D. N. Oko, S. Garbarino, R. Imbeault, M. Chaker, A. C. Tavares, D. Guay and D. Ma, J. Phys. Chem. C, 2012, 116, 13413-13420.

5 Z. Peng, B. Spliethoff, B. Tesche, T. Walther and K. Kleinermanns, J. Phys. Chem. B, 2006, 110, 2549-2554.

6 B. Zugic, L. Wang, C. Heine, D. N. Zakharov, B. A. J. Lechner, E. A. Stach, J. Biener, M. Salmeron, R. J. Madix and C. M. Friend, Nat. Mater., 2017, 16, 558-564.

7 X. Huang, Z. Zhao, L. Cao, Y. Chen, E. Zhu, Z. Lin, M. Li, A. Yan, A. Zettl, Y. M. Wang, X. Duan, T. Mueller and Y. Huang, Science, 2015, 348, 1230-1234.

8 R. He, Y. C. Wang, X. Wang, Z. Wang, G. Liu, W. Zhou, L. Wen, Q. Li, X. Wang, X. Chen, J. Zeng and J. G. Hou, Nat. Commun., 2014, 5, 4327.

9 C. Cui, L. Gan, M. Heggen, S. Rudi and P. Strasser, Nat. Mater., 2013, 12, 765-771.

10 D. Alloyeau, C. Ricolleau, C. Mottet, T. Oikawa, C. Langlois, Y. Le Bouar, N. Braidy and A. Loiseau, Nat. Mater., 2009, 8, 940-946.

11 S. Ma, M. Sadakiyo, M. Heima, R. Luo, R. T. Haasch, J. I. Gold, M. Yamauchi and P. J. A. Kenis, J. Am. Chem. Soc., 2017, 139, 47-50.

12 P.-C. Chen, X. Liu, J. L. Hedrick, Z. Xie, S. Wang, Q.-Y. Lin, M. C. Hersam, V. P. Dravid and C. A. Mirkin, Science, 2016, 352, 1565-1569.
13 K. Kusada, M. Yamauchi, H. Kobayashi, H. Kitagawa and Y. Kubota, J. Am. Chem. Soc., 2010, 132, 15896-15898.

14 K. Kusada, H. Kobayashi, R. Ikeda, Y. Kubota, M. Takata, S. Toh, T. Yamamoto, S. Matsumura, N. Sumi, K. Sato, K. Nagaoka and H. Kitagawa, J. Am. Chem. Soc., 2014, 136, 1864-1871.

15 K. Kusada and H. Kitagawa, Adv. Mater., 2016, 28, 1129-1142.

16 Q. Zhang, K. Kusada, D. Wu, T. Yamamoto, T. Toriyama, S. Matsumura, S. Kawaguchi, Y. Kubota and H. Kitagawa, Nat. Commun., 2018, 9, 510.

17 S. Masuda, K. Shun, K. Mori, Y. Kuwahara and H. Yamashita, Chem. Sci., 2020, 11, 4194-4203.

18 F. Wang, K. Kusada, D. Wu, T. Yamamoto, T. Toriyama, S. Matsumura, Y. Nanba, M. Koyama and H. Kitagawa, Angew. Chem., 2018, 130, 4595-4599.

19 Q. Zhang, K. Kusada, D. Wu, N. Ogiwara, T. Yamamoto, T. Toriyama, S. Matsumura, S. Kawaguchi, Y. Kubota, T. Honma and H. Kitagawa, Chem. Sci., 2019, 10, 5133-5137. 20 F. Studt, F. A. Pedersen, T. Bligaard, R. Z. Sørensen, C. H. Christensen and J. K. Nørskov, Science, 2008, 320, 1320-1322.

21 C. van der Wijst, X. Duan, I. S. Liland, J. C. Walmsley, J. Zhu, A. Wang, T. Zhang and D. Chen, ChemCatChem, 2015, 7, 2991-2999.

22 L. Jia, J. Yu, Y. Chen, P. Ning, Q. Guan, J. Gu, R. Miao and Q. Chen, J. Supercrit. Fluids, 2017, 126, 79-88.

23 S. Jana, J. W. Chang and R. M. Rioux, Nano Lett., 2013, 13, 3618-3625.

24 H. Okamoto, J. Phase Equilib., 2003, 24, 280-281.

25 C. Schöttle, P. Bockstaller, R. Popescu, D. Gerthsen and C. Feldmann, Angew. Chem., 2015, 127, 10004-10008.

26 C. Schöttle and C. Feldmann, Z. Anorg. Allg. Chem., 2016, 642, 555-559.

27 C. Schöttle, F. Gyger and C. Feldmann, Chem. Ing. Tech., 2018, 90, 427-435.

28 S. Kawaguchi, M. Takemoto, K. Osaka, E. Nishibori, C. Moriyoshi, Y. Kubota, Y. Kuroiwa and K. Sugimoto, Rev. Sci. Instrum., 2017, 88, 085111.

29 P. Nash and Y. Y. Pan, Bull. Alloy Phase Diagrams, 1987, 8, 422-430. 